\title{
Occupational medicine's role in return to work of the nurse bitten by belgian sheperds: Report of a case
}

\author{
Lalić Hrvoje, Šutić Ivana, Tominić Jana \\ Medical School University Rijeka, Croatia
}

Received: June 5, 2017

Accepted: June 29, 2017

Online Published: July 4, 2017

DOI: $10.5430 /$ cns.v5n3p41

URL: https://doi.org/10.5430/cns.v5n3p41

\begin{abstract}
The aim is to accentuate the role of Occupational medicine (OM) when establishing fitness for work. A nurse, now 55, in 2014 was attacked by two Belgian Shepherds whilst picking asparagus in woods. She suffered scalp (still today partially without hair) and thorax injuries and on extremities partial and permanent muscles loss. She was treated by a surgeon, neurologist, psychologist, and psychiatrist. Applied were Cognitive Non - Verbal Test (CNT), Minnesota Multiphasic Personality Inventory (MMPI-201), Stress Perception Scale (PSS-10) and Beck's depression inventory. The patient is on sick leave since March 2014. In December 2015 she came to OM specialist for work assessment. After suffering polytrauma it was suggested she takes on a less demanding job for the beginning of reintegration. Although unstable and walking with a crutch, the patient expressed strong will to go back to work. The management at the time did not find appropriate workplace for her, so she stayed on sick leave until April 2017. Then the new OM assessment was demanded. CNT showed that general intellectual efficacy is preserved and that the functioning is on the average level. MMPI showed increased levels for hypochondria, anxiety, aggressiveness, schizoid behavior and conversion. At the end, it was concluded that at present the patient was not capable to work as a nurse for now, but she could work as a clerk. The patient fully accepted that decision as well as the new management.
\end{abstract}

Key Words: Assessment of working capacity, Occupational medicine, Polytrauma

\section{INTRODUCTION}

Big German Shepherds and similar dogs can cause heavy bodily harm as well as psychical trauma. They can appear immediately but can also remain dormant and reappear after many years. ${ }^{[1]}$ The more severe injuries are, the psychopathological reaction of organism is stronger and more frequent. ${ }^{[2]}$

Animal bytes require psychological, anesthetic and surgical treatment in children as well as in adults. ${ }^{[3]}$ Such bytes are infectious and require urgent treatment.

In this paper is presented the case of a nurse, 52 years old, attacked by two Belgian Shepherds. She suffered polytrauma with posttraumatic stress disorder - (PTSD). After three years of continuous sick leave in the Department of Occupational medicine, serious effort has been made to assess the state of her health condition again and establish whether she was fit to take on a less demanding job, for the beginning as an administrative clerk.

\section{REPORT OF A CASE}

In March 2014, whilst picking asparagus in the woods, a 52 years old nurse was attacked by two loose Belgian Shepherds. As a consequence she suffered numerous polytrauma and a hemorrhagic shock. She suffered scalp injuries, multiple bites of the neck, thorax and upper and lower extremities (see Figures 1 and 2).

*Correspondence: Lalić Hrvoje; Email: hlalic@ inet.hr; Address: Brentinijeva 5/III, Rijeka 51000, Croatia. 


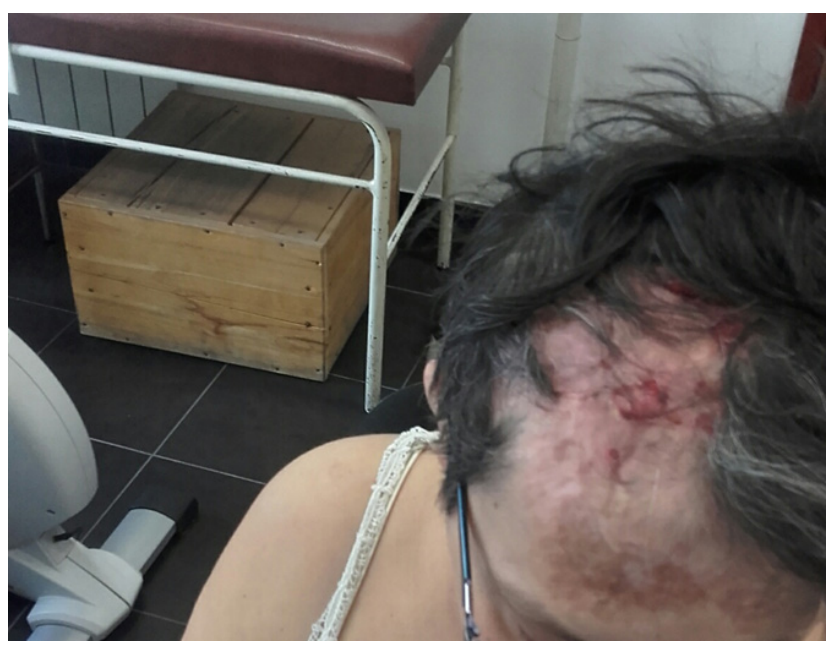

Figure 1. Scars of the scalp caused by bites of Belgian Shepherds

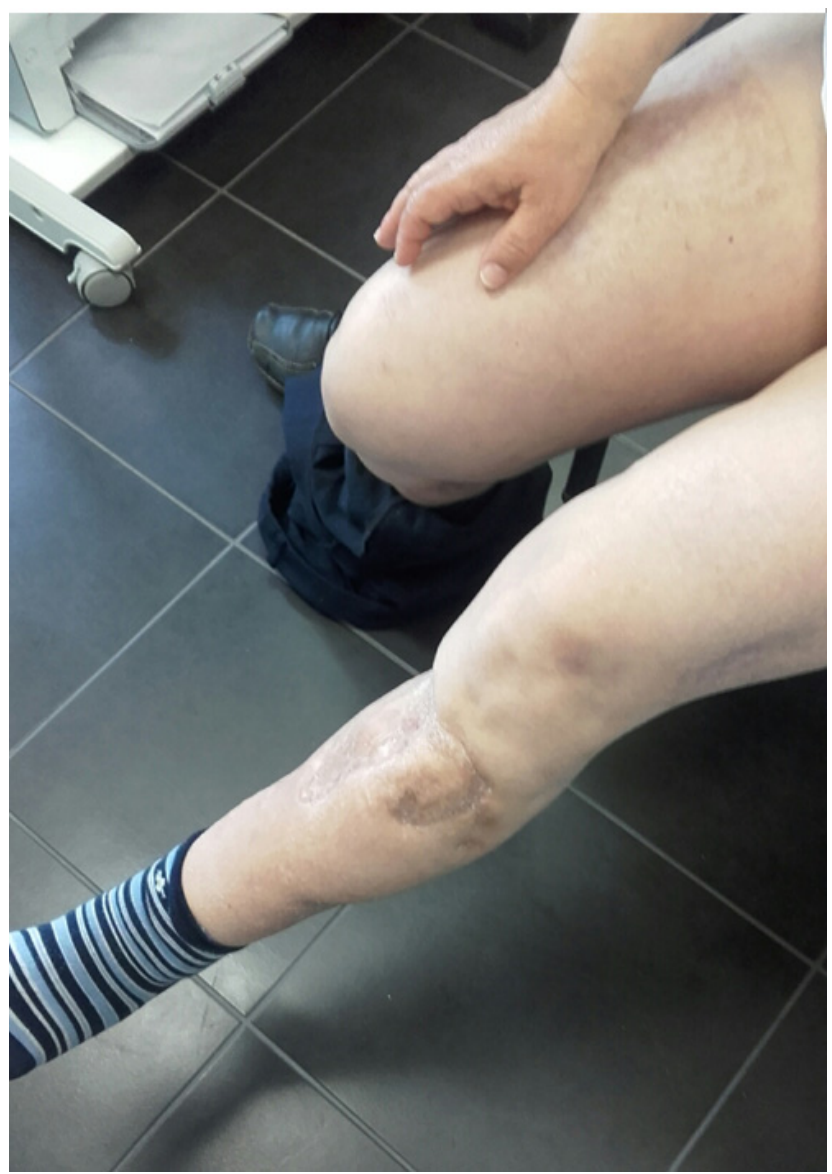

Figure 2. The lower extremities injuries by bites of Belgian Shepherds

The nurse was examined at the Department of Occupational medicine in order to assess her remaining work capacity in December 2015. Although the patient was severely injured and suffered polytrauma, developed PTSD with serious symptoms of insomnia, nightmares, fears, withdrawal, she expressed a strong desire to overcome all of those and to improve her health. She underwent a psychiatric and psychological treatment and eventually the above mentioned symptoms had withdrawn. At the time of examination the patient did not feel capable psychically or physically to restart her work as a nurse. Furthermore, direct contacts with medical patients are sometimes very stressful, so she asked to be relocated to an administrative job to work as a clerk. The Health Centre management at the time was not inclined to give the nurse patient such a job, so she remained on sick leave. In April 2017, she was again referred to the Department of Occupational medicine for a new health and work capacity assessment.

At the Department of Occupational medicine the nurse was again examined, and she underwent numerous psycho tests. They were Cognitive Non - Verbal Test (CNT) test, ${ }^{[4]}$ Minnesota Multiphasic Personality Inventory (MMPI-201) test, ${ }^{[5]}$ Stress Perception Scale (PSS-10) test ${ }^{[6]}$ and Beck's depression scale. ${ }^{[7]} \mathrm{CNT}$ and PSS-10 showed regular results, while MMPI showed anxious - depressive shift as well as Beck's showed borderline to moderate depression.

\section{DiscuSSION}

The Occupational medicine (OM) in this case has the key role in assessing the patient's remained work capacity. The triangle, patient - OM specialist - the firm/institution manager is of extraordinary importance.

During such a long term sick leave, three years in total, the support of the general practitioner (GP) is not to be neglected.

GPs can also play an important role in facilitating one's return to work, improving outcomes for all parties - the patient, work insurer, medical provider. ${ }^{[8]}$

However, a leading profession in the medicine that decides about returning to work or about the permanent retirement is OM. OM, besides functional capacity diagnostic set, in its team has a psychologist and a psychiatrist whose opinion is necessary in establishing the final assessment on work capacity. This way OM consolidates the state of the patient and makes its final decision.

It is true that health care providers (HCPs) play a central role in workers' compensation claims. ${ }^{\text {[9] }} \mathrm{OM}$ with its academic and professional education as well as equipped with different types of psychological and functional tests, takes the leading position in assessment of work capacity.

Injured workers with long term complex injuries experience difficulties with healthcare in the workers' compensation context. $^{[10]}$ 
For that reason the patient should return to work as soon as possible. If the quick return to work is not possible, as in the case of the injured nurse who endured a 3 years long healing period along with repeated transplantations, psychological and psychiatric treatment, it is necessary to assess the remaining work capacity.

Preserved mental capacities are the basis for returning to work. The general preserved intellectual efficacy is obtained by the CNT test. The above mentioned patient functions on the average level of examinees between 51 - 65 years old.

The personality profile demonstrates preoccupancy with so- matic disorders and the anxious - depressive shift, reduced tolerance to frustration and lowered adaptive potentials in stressful circumstances.

The MMPI-201 showed high validity, all the control scales of measurement (lies, bizarre responses, retention) were bellow $\mathrm{T}$ score -70 , and less of six clinical scales of measurements were above $\mathrm{T}=70$.

On the revised MMPI-201 table, especially accentuated are peaks for hypochondria ( $\mathrm{Hs})$, anxiety $(\mathrm{Pt})$, aggressiveness $(\mathrm{Pd})$, Schizoid behavior (Sc) and for conversion (Hy) (see Figure 3).

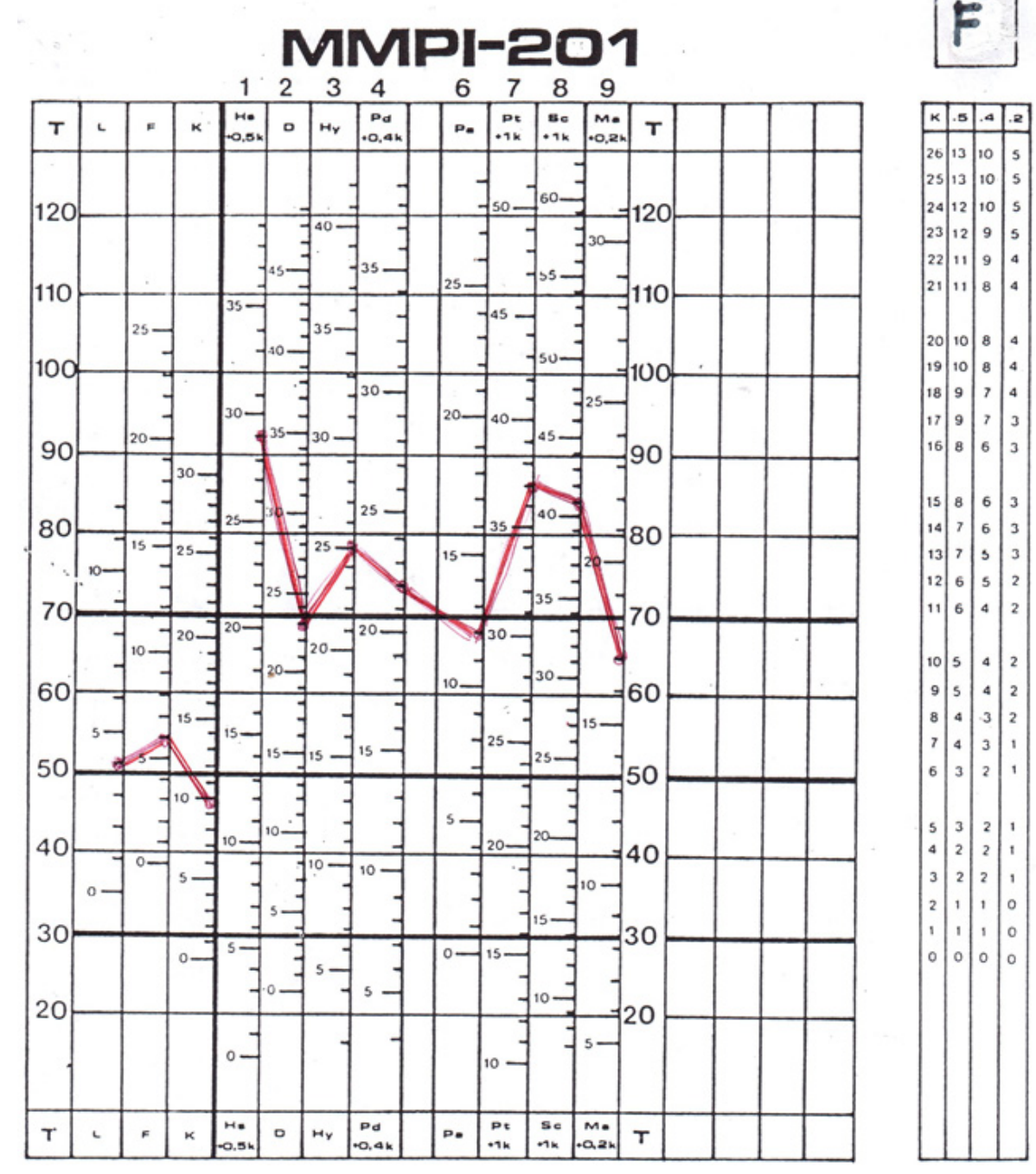

Figure 3. The revised MMPI-201 Inventory

The peak for aggression is connected to angriness about the accident and with the irresponsible dog owner, whom she took to court and where the proceedings are still not over. There is also angriness with former management that had not found another, more adequate job for her, as well as with the whole medical system in general. In the beginning all the physicians were around her and they took care of her, but today nobody cares any longer and she feels abandoned, it seems to her that she is expected to pay for her reconstructive surgery by herself, the expense she cannot afford. 
The above mentioned angriness is not difficult to explain. The patient is in constant muscle pain, suffers paresthesia, oozing wound and static instability, thus the presence of hypochondria is not surprising. She is afraid of possible future reconstructive surgery.

She would like to work but is aware that at present she is not capable to work as a nurse in the present moment. The work of a nurse is a complex and varied job and it demands a physically fully able person who can follow and collaborate with doctor, manage occasional stressful contacts with patients as well as manage triage in the waiting room, etc. The above mentioned patient is a positive person; she still wishes to contribute to the community, and is prepared to take on a job as an administrative clerk for now.

During her sick leave and the time she spends alone, the patient is reliving her dog attack ordeal and has nightmares, which is typical for such a trauma. Schizoid traits could also be explained as the consequence of heavy traumatic experience during dog attack. Not only dog but also cat attacks could leave serious consequences on one's health, as it had been described. ${ }^{[11]}$

The patient further states that she had completely distanced herself from her husband, it is embarrassing for her that he sees her without the wig, and she cannot even imagine going to the beach and undressing in front of other people.

In order to conduct a proper evaluation, it is important for the medical practitioner to also know the patient's psychosocial factors. ${ }^{[12]}$

During sick leave the patient's income is significantly reduced.

The OM doctor in cooperation with a psychologist has meticulously examined the patient and in further cooperation with the Health Center's new management came to conclusion that the patient is fit to work as an administrative clerk. Due to combined efforts of all three parties the patient will after three years of sick leave return to work.

Medical nursing profession belongs to jobs under special work conditions and as such is subject to previous, periodic and when necessary extra examinations at the branch of OM. The nurse described above came to $\mathrm{OM}$ for extra examination in order to have assessed her remaining work capacity.

The presentation of this case is an example of the significance of OM which in team examination with other specialists assesses the level of remaining work fitness in the patient. Naturally, the positive attitude of the patient and the willingness to go back to work is also important. To start it is suggested the patient takes on an administrative job at a health centre. It is believed that reintegrating the patient in work process shall benefit the patient's psychophysical state, thus opening the possibility to return to her job as a medical nurse in a doctor's team whilst regularly screened by her OM and GP doctors.

Gradual return to work with the aim to enable the patient to again take on nursing is a case of a successful example of OM work. Medical nursing presents one of the underlying pillars of health care and highly qualified nurses as well as social community invest a large effort and means into their education.

Contrary to the case presented, OM does not allow remaining in employment to persons whom are under the threat of health damage even when medical and disability committees ask so. ${ }^{[13]} \mathrm{OM}$ is completely impartial and objective and OM specialists are often asked for their expert opinion in court proceedings.

\section{Conclusions}

To conclude, this case presents the significance of "fight" with help of OM to return to work of a heavy wounded nurse attacked by dogs, temporarily to an easier job but with a view of going back to nursing. Medical nursing has become a deficit profession and without it the whole medical system would be unsustainable.

\section{Conflicts of Interest Disclosure}

The authors declare they have no conflict of interest.

\section{REFERENCES}

[1] Jovanović AA, Ivković M, Gašić MJ. Posttraumatic stress didorder in World War II concentrationb camp survivor caused by the attack of two German shepherd dogs: case report and review of literature. Forensic Sci Int. 2011; 208(1-3): e15-9. https://doi.org/10.1 016/j.forsciint.2011.02.016

[2] Ji L, Xiaowei Z, Chuanlin W, et al. Investigation of posttraumatic stress disorder in children after animal-induced injury in China. Pedi- atrics. 2010; 126(2): e320-4.

[3] Touzet-Roumazeille S, Jayyosi L, Plenier Y, et al. Surgical management of animal bytes in children. Ann Chir Plast Esthet. 2016; 61(5): 560-567. https://doi.org/10.1016/j.anplas.2016.06.013

[4] Naklada Slap Jastrebarsko [Cognitive non-verbal test, in Croatian]. 2004;1-49.

[5] Biro M. Zagreb/Belgrade: Medicinska knjiga. [Clinical psychology in Croatian]. 1990; 7-114. 
[6] Cohen S, Kamarick T, Mermelstein R. A global measure of perceived stress. J Health Soc Beh. 1983; 24(4): 385-96.

[7] Kumar G, Rissmiller DJ, Steer RA, et al. Mean Beck Depression Inventory-II total scores by type of bipolat episode. Psychol Rep. 2006; 98(3): 836-40. PMid: 16933681. https://doi.org/10.2 $466 / \operatorname{pr} 0.98 .3 .836-840$

[8] Fenner P. Returning to work after an injury. Aust Fam Physician. 2013; 42(4): 182-5. PMid: 23550239.

[9] Kosny A, MacEachen E, Ferrier S, et al. Thew role of health care providers in long term and complicated workers' compensation claims. J Occup Rehab. 2011; 21(4): 582-90.
[10] Kilgfour E, Kosny A, McKenzie D, et al. Healing or harming? Healthcare provider interactions with injured workers and insurers in wotkers' compensation systems. J Occup Rehabil. 2015; 25(1): 220-39. https://doi.org/10.1007/s10926-014-9521-x

[11] Hanauer DA, Ramakrishnan M, Seyfried LS. Describing the relationship between cat bytes and human dpresion using dana from an electronic health record. PloS One. 2013; 8(8): e70585.

[12] Geisser ME, Robinson ME, Miller QL, et al. Psychosocial factors and functional capacity evaluation among persons with chronic pain. J Occup Rehab. 2003; 13(4): 259-76. https://doi.org/10.1023/A : 1026272721813

[13] Lalić H. Expert assessment of war casualties. Med Sci Law. 2017; 57(1): 47-51. 